\title{
Ese oscuro objeto del deseo colectivo.
}

Acerca de Las metamorfosis de Saturno. Transformaciones de la utopía en la literatura italiana contemporánea, de Daniel Del Percio. Buenos Aires: Miño y Dávila, 2015, 351 pp. ISBN: 978-84-15295-47-1.

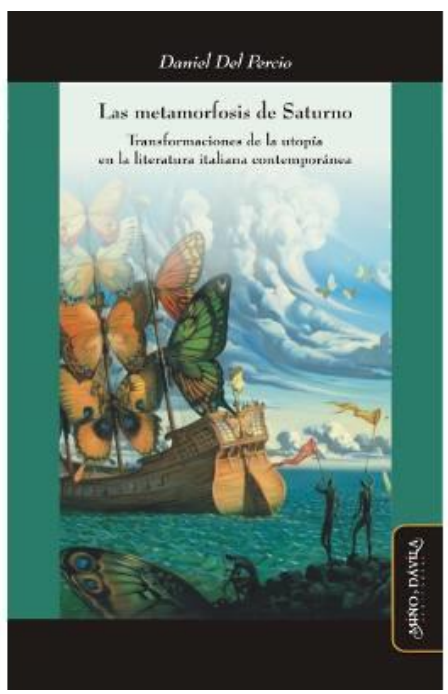

Lucía Puppo ${ }^{1}$ UCA - CONICET

Material original autorizado para su primera publicación en el Journal de Ciencias Sociales, Revista Académica de la Facultad de Ciencias Sociales de la Universidad de Palermo.

¿De qué hablamos cuando hablamos de utopía? La reacción espontánea frente a esta palabra recuerda la expresión de San Agustín respecto del tiempo: "Si nadie me lo pregunta, lo sé; si quiero explicarlo a quien me lo pide, no lo sé".

Ante la carencia de una definición científica, quizás busquemos apoyo en los textos conocidos. Recordaremos entonces la visión de Isaías:

\footnotetext{
${ }^{1}$ Dra. en Letras, Investigadora del CONICET y Profesora de Teoría de la Comunicación y de Teoría y Análisis del Discurso Literario en la Universidad Católica Argentina.
} 
Habitará el lobo con el cordero, y el leopardo se acostará con el cabrito, y comerán juntos el becerro y el león, y un niño los pastoreará [...] No habrá ya más daño ni destrucción en todo mi monte santo, porque estará llena la tierra del conocimiento de Yavé, como llenan las aguas el mar. ${ }^{2}$

\section{O acaso venga a nuestra mente la pregunta de Tomás Moro:}

... ¿̇qué justicia es la que permite que cualquier noble, banquero, usurero u otro semejante de los que nada hacen, o que si algo hacen no tiene gran valor para la República, lleve una vida espléndida y deliciosa, en la ociosidad o en ocupaciones superfluas, mientras el obrero, el carretero, el artesano y el campesino han de trabajar tanto y tan asiduamente en labores propias de jumentos...? ${ }^{3}$

¿De qué hablamos cuando hablamos de utopía? ¿De la felicidad bucólica que cantaba el profeta, o de un estado delineado por los valores humanistas? Jardín, Edad Dorada, Tierra de la Abundancia, Paraíso prometido, Sueño de una República Perfecta, Proyecto para una Sociedad Ideal: como sutiles metamorfosis de Saturno, los motivos utópicos impregnan los imaginarios de la religión, la filosofía, la política, el arte y la literatura en Occidente. Dado este panorama tan vasto, atravesado por incontables analogías y equívocos, el libro de Daniel Del Percio aborda la utopía como objeto de estudio interdisciplinario. Su foco de interés específico es la utopía literaria, entendida esta como un sistema complejo, articulado en forma de narración ficcional, que pretende zanjar la distancia entre lo social y lo individual, entre lo humano y lo político, entre la cultura y sus relatos.

El volumen arroja los resultados de una investigación exhaustiva y minuciosa, que fue ganando matices con el paso de los años. Así lo pone en evidencia la Primera Parte, que luego de la Introducción presenta un capítulo inicial que lleva por título "La lógica formal de la Utopía". Se trata de un texto programático que, después de ofrecer un imponente estado de la cuestión, abre el juego para la exploración de hipótesis inéditas. Con el objetivo de brindar una definición propia de la utopía literaria, el autor desgrana los diferentes "estratos" o "capas" que se superponen en el terreno a observar. De ese modo se va desplegando una auténtica arqueología del saber utópico, que invita a pensar e incluso a reformular determinados argumentos: la inexistencia o imposibilidad de la utopía como su verdadera potencia, las fronteras lábiles entre lo real y lo imaginario, la confluencia de nostalgia del pasado y racionalismo futurista. En el derrotero teórico-crítico, ideología y utopía se revelan como principios complementarios que conforman una narrativa, en tanto que el vínculo con el género relato de viaje permite concluir que el itinerario es un elemento omnipresente y estructurante de lo utópico.

\footnotetext{
${ }^{2}$ Versículos extraídos de Isaías 11, 6-9. Sagrada Biblia. Traducción de E. Nacar Fuster y A. Colunga Cueto. Madrid: BAC, 1980.

${ }^{3}$ Tomás Moro, Utopía. Traducción y notas de Ramón Esquerra. Madrid: Círculo de Bellas Artes, 2011, pp. 195-196.
} 
Daniel Del Percio se vale de herramientas metodológicas diversas, provenientes de la Historia Literaria, la Semiótica, la Estética de la Recepción, la Filosofía de Michel Foucault, Giorgio Agamben y Gianni Vattimo, la Hermenéutica de Paul Ricœur y la Teoría de los Mundos Posibles en las variantes cultivadas por Umberto Eco, Thomas Pavel y Lubomír Doležel, entre otros. Su abordaje de la utopía no elude algunas cuestiones problemáticas, como es el caso de su relación con el fantasy, la distopía o el símbolo de la metamorfosis. Explica el autor que la dimensión histórica del fenómeno utópico es inseparable de su faceta mítica y metafísica. En su tejido confluyen aspectos prospectivos (lo pensable, lo deseable) y retrospectivos (la memoria de los hechos), todos estrechamente ligados a su contexto de producción y recepción.

La Segunda Parte del libro se centra en tres utopías clásicas de la literatura italiana. Itinerarium mentis in Deum es la fórmula con que Del Percio resume los esbozos de relato utópico que traza la Commedia de Dante Alighieri. En el movimiento, primero descendente y luego ascendente, de Dantepersonaje adivina el deseo y la identidad que cifran la promesa del Dante-autor, peregrino exiliado que mediante la palabra se afirma en ese Amor último que mueve al sol y a las estrellas. Por otra parte, el Itinerarium mentis in nusquam sintetiza la propuesta que anima La Città del Sole, del dominico Tommaso Campanella. Surgida en el ámbito de la Contrarreforma, esta utopía encarna la (para nosotros) paradójica e íntima relación entre ciencia, exploración y ciencias ocultas. Finalmente, el Itinerarium mentis in ruinas cristaliza el desencanto del mundo en la poesía y la prosa de Giacomo Leopardi. El oído fino de Daniel Del Percio, poeta él también, favorece una lectura novedosa del "dulce naufragar" que inauguró el poeta romántico por excelencia.

Un acierto notable de la investigación de Del Percio consiste en presentar estos corpus canónicos, representativos de tres momentos claves de la cultura y la historia italianas, en diálogo con tres figuras descollantes de la literatura contemporánea. Así resulta que la Tercera Parte del volumen se lee "en espejo" con la Segunda, mediante la réplica de su estructura tripartita. En primer lugar, el trayecto iluminado de Dante coincide con la búsqueda de lo absoluto que hilvana de libro en libro Mario Luzi, poeta y ensayista que supo articular su obra en torno a los ejes de la Simplicidad y la Caridad. ${ }^{4}$ En sus textos el Infierno se revela como un presente doloroso que el poeta debe atravesar, y el Limbo, en cambio, como una proyección narcisista, cerrada a lo trascendente. En la mística posmoderna desarrollada por Luzi resulta fundamental la mediación de las imágenes; de allí el protagonismo que adquiere en uno de sus poemarios el arte de Simone Martini.

\footnotetext{
${ }^{4}$ Daniel Del Percio retoma la tesis postulada por Massimo Cacciari en "Simplicitas e Caritas nella poesia di Mario Luzi". En Luzi, Mario. Autoritratto. Note critiche. Milán: Garzanti, pp. 379-386
} 
El segundo itinerario, análogo al viaje a la isla imposible de Campanella, es el que trazan algunos hitos de la narrativa de Italo Calvino. El capítulo dedicado a este autor examina el poder de la descripción que convierte al lector en un espectador inquieto, así como la fascinación del escritor por Oriente, el laberinto borgeano y la Metaciudad de Fourier. Bajo la lupa del análisis, la utopía que plantean Las ciudades invisibles resulta ser el algoritmo que permite descifrar la combinatoria de los fragmentos.

El tercer itinerario, que remite al trayecto entre ruinas de Leopardi, es el que perfilan los textos híbridos, a medio camino entre el relato y el ensayo, de Claudio Magris. Señala Del Percio que en la poética de este autor, la utopía aparece asociada a la Historia con mayúscula, sumatoria de las pequeñas historias individuales. Puede asumir la variante del río que escriben todos los hombres, en El Danubio, o la opción por el viaje infinito, en Alla cieca. La prosa melancólica y decantada de Magris parece confirmar que, en nuestra época, la utopía equivale al recuento de los fósiles del presente.

Por todo lo dicho, Las metamorfosis de Saturno. Transformaciones de la utopía en la literatura italiana contemporánea ofrece una serie de reflexiones largamente maduradas sobre un tópico fascinante. Sin dudas su existencia nos habla de un presente fértil y un futuro prometedor para los estudios italianistas y de literatura comparada en nuestro país, y estimamos que un trabajo de esta envergadura será particularmente apreciado por los especialistas de otras disciplinas que se abocan al estudio de lo utópico. Aunque nos atrevemos a afirmar que su escritura delicada y precisa, atenta a los detalles sin perder de vista la amplitud de la materia tratada, ejercerá una atracción poderosa sobre todos los lectores que se acerquen a sus páginas. En ellas opera, a fin de cuentas, la seducción de la utopía, posibilidad de un mundo mejor que anhelamos, en lo más recóndito de nuestro ser, los hombres y las mujeres de todos los tiempos. Para decirlo en las acertadas palabras de Daniel Del Percio: “Una Utopía es una segunda lengua de la realidad, una forma de hablar de ella a partir de los sueños o pesadillas que promete o sufre, una construcción que nos permite ver la destrucción y la reconstrucción necesarias en todo cambio, y poder medir su costo y su premio". ${ }^{5}$

\footnotetext{
${ }^{5}$ Daniel Del Percio, Las metamorfosis de Saturno. Transformaciones de la utopía en la literatura italiana contemporánea. Buenos Aires: Miño y Dávila, 2015, p. 336.
} 